\title{
Arbor
}

\section{Las Comunidades Autónomas y la solidaridad interterritorial, bases para la política sanitaria}

\author{
Ana María Pastor Julián
}

Arbor CLXXX, 710 (Febrero 2005), 397-401 pp.

El Sistema Nacional de Salud empezó a cobrar plena realidad a partir de la transferencia de competencias culminada por el Gobierno del Partido Popular en Diciembre de 2001, acompañada de un modelo de financiación que, por cierto, fue acordado con todas las Comunidades Autónomas que está dotado de mecanismos que permiten su actualización y suficiencia.

Ante esta nueva realidad institucional se hacía imprescindible asegurar la calidad asistencial y la equidad territorial, de modo que los ciudadanos se vieran en todo caso beneficiados por una gestión sanitaria más cercana y eficiente, pero con sus riesgos de desigualdades según el lugar en el que se encuentren.

Fue precisamente ese del motivo fundamental que llevó al Gobierno del Partido Popular a promover un marco normativo que ofreciera garantías plenas tanto a la Administración Sanitaria del Estado como a las de las Comunidades Autónomas; tanto a los profesionales como a los pacientes.

El marco nuevo normativo debía ofrecer al mismo tiempo los cauces adecuados para la cooperación y la coordinación entre las Administraciones sanitarias y hacer posible la necesaria participación social.

Los cambios que demanda una Sanidad dinámica, una Sanidad que avance en investigación, en calidad asistencial, en la lucha contra las enfermedades y en la promoción de la salud encontró, en efecto, en la Ley de Calidad y Cohesión del Sistema nacional de Salud su mejor instrumento.

El año 2003 fue conocido por el año de las leyes sanitarias, porque, además de la Ley de cohesión y calidad, se aprobaron otras leyes que res- 
pondían a estos mismos objetivos, poniendo el acento en los profesionales sanitarios y en la solución a múltiples problemas pendientes desde la Ley General de Sanidad de 1986.

Me refiero a la Ley de Ordenación de las Profesiones Sanitarias y al Estatuto Marco, que no solo aporta mecanismos para resolver las cuestiones pendientes, sino que lo hacen teniendo en cuenta la realidad decentralizadora del Estado de las Autonomías, que comporta competencias de las Comunidades Autónomas, pero que también exige cohesión territorial para que el Sistema Nacional de Salud sea algo real y no una nueva entelequia.

Con todo, la clave para el buen funcionamiento del Sistema Nacional de Salud está en ese órgano de impulso, de coordinación y de cooperación que es el Consejo Interterritorial, en el que el Ministerio de Sanidad y Consumo y las Comunidades Autónomas tienen la responsabilidad de llevar a buen puerto la Sanidad española.

El respaldo de la Ley de Cohesión y Calidad del Sistema Nacional de Salud al Consejo Interterritorial es patente, lo mismo que la forma de apoyarlo cuando tuve la responsabilidad de presidirlo como Ministra.

Hoy más que nunca hemos de pedir que se recupere el papel del Consejo Interterritorial y, que deje de ser un mero Foro de encuentro para «conocer» y "recibir información» de un Ministerio que vive horas bajas en lo que se refiere a decisiones y medidas a favor de a salud de los ciudadanos.

En cualquier caso, desde el Partido Popular se ha querido mantener lo más positivo de estos planteamientos, tanto a nivel parlamentario como en la gestión de las Comunidades Autónomas en las que gobernamos.

En esta etapa en que el PP está a nivel nacional en la oposición hemos querido desde un principio contribuir al mantenimiento de un Sistema Nacional de Salud calificado por la OMS como el séptimo mejor del mundo.

Pruebas concretas de ello podemos aportar, aunque los ciudadanos son los que mejor lo saben.

Esa forma de ver el funcionamiento solidario de nuestro Sistema nacional de Salud y de hacer entre todos que nuestra Sanidad ofrezca nuevos logros en beneficio de los ciudadanos está sintetizada en el «decálogo» de principios que los Consejeros del PP y yo misma tuvimos ocasión de suscribir en abril de 2004 en Mallorca.

En base a la recíproca lealtad institucional y empleando todas las posibilidades que da el método del diálogo abierto, los Consejeros del PP respaldaron los siguientes principios: 
1. Aplicación y total respeto a la Ley de Cohesión y Calidad del Sistema Nacional de Salud, configurada como un instrumento básico para garantizar la equidad, calidad y participación social en el Sistema Nacional de Salud.

2. Configurar al ciudadano como centro del Sistema Nacional de Salud, anteponiendo sus intereses y la satisfacción de sus demandas como función primordial del mismo.

3. Potenciación de los recursos humanos que prestan servicio en el Sistema Nacional de Salud, partiendo de la premisa de que constituyen el principal activo de las Administraciones Públicas. Para ello, se adquiere el compromiso de desarrollar acciones dirigidas a desarrollar su carrera profesional, adecuar su capacitación al desarrollo de las nuevas tecnologías y técnicas de diagnóstico y mejorar sus condiciones de empleo, así como planificar las necesidades de efectivos de conformidad con las demandas sociales.

4. Garantizar la suficiencia y el equilibrio financiero del sistema, considerando este principio como una de las cuestiones primordiales para la perviviencia del mismo. Para ello, las CCAA se comprometen a aplicar criterios de gestión dirigidos a hacer realidad dicha suficiencia, planificando y ejecutando para ello políticas públicas que la respetan, exigiendo a los órganos competentes de la Administración General del Estado medidas homogéneas que garanticen estos principios desde el reconocimiento de las diferentes realidades de las distintas CCAA.

5. Aplicar criterios de solidaridad territorial en el desarrollo de las políticas públicas autonómicas en materia de sanidad, teniendo presente que el Sistema Nacional de Salud está constituido por la suma de todos los de las regiones y de todos los ciudadanos. Para ello, se considera fundamental la potenciación del Consejo Interterritorial del Sistema Nacional de Salud como órgano de participación, debate y coordinación, con el objetivo de garantizar la continuidad de dicho sistema y la eficaz aplicación de políticas que contemplen la solidaridad entre las diferentes partes de España.

6. Control del gasto farmacéutico, estableciendo fórmulas que permitan controlar su evolución y evitar su incremento, todo ello sin perjuicio de atender las demandas que presenten los usuarios del sistema y de apostar por la potenciación de la industria farmacéutica como sector relevante de la economía española.

7. Diseño de planes para la construcción de infraestructuras y para la mejora de las existentes, adecuándolas a las necesidades asis- 
tenciales de la población y configurando sistemas que permitan adaptar los recursos a las demandas cambiantes.

8. Mejora continua de la calidad asistencial, estableciendo sistemas para su medición y corrección de aquellas desviaciones que se produzcan e incorporación de las nuevas tecnologías a la asistencia sanitaria, diseñando planes de mejora que permitan la mejora constante de los medios materiales.

9. Configuración de las políticas de Salud Pública como una cuestión de Estado ajena al debate político y promoción del diseño y ejecución de actuaciones en esta materia, considerando su protección como un derecho fundamental de todos los españoles que debe ser garantizado pór los poderes públicos.

10. Desarrollo de planes especiales para paliar carencias concretas, así como diseño de una política activa y eficaz en materia de prevención de enfermedades, considerándola como un factor clave en la educación de las nuevas generaciones.

Creo que cada uno de esos 10 principios es suficientemente elocuente de cual es nuestra voluntad política, de cuáles son las vías por las que queremos lograr la Sanidad que se merecen los ciudadanos españoles.

Es cierto que hemos tenido y estamos teniendo graves dificultades de proyectar esos principios y esa voluntad de diálogo en el seno del Consejo Interterritorial.

También es cierto que temas cruciales como el de la financiación sanitaria o la política farmacéutica caminan por otros derroteros (globos sonda y sordera total), pero hemos querido contribuir a la mejora del Sistema Nacional de Salud a través de una serie de Foros Sanitarios que nuestras Comunidades Autónomas han venido convocando para debatir con profundidad y sin restricciones los temas que preocupan al mundo sanitario en España:

$>$ La atención primaria.

$>$ La política farmacéutica y las ventajas del sistema de precios de referencia.

$>$ La financiación del sistema Nacional de Salud.

$>$ Los recursos humanos del Sistema y el futuro de las profesiones sanitarias.

$>$ Y próximamente la eficiencia y la calidad en la gestión.

Vamos a seguir apostando por el papel de las Comunidades Autónomas en el ámbito sanitario; por un eficaz Consejo Interterritorial abierto 
Las Comunidades Autónomas y la solidaridad...

a la colaboración y sin restricciones, por una financiación sostenible, que tenga en cuenta los cambios demográficos y otros factores poblacionales (inmigración, dispersión geográfica, patrón epidemiológico, etc.); por la aprobación e unos criterios comunes que permitan la movilidad de las profesiones en base a una visión moderna de carrera profesional; por la aprobación del Fondo de Cohesión, y por el respaldo a la investigación biomédica, sin sobresaltos ni tasas inconstitucionales.

Esta es la forma en la que, desde el Partido Popular, creemos que debería fortalecerse el Sistema Nacional de Salud. Los principales beneficiarios: los ciudadanos. 